\title{
A BODIPY**-Based Fluorescent Probe to Visually Detect Phosgene: Toward the Development of a Handheld Phosgene Detector
}

\author{
Melike Sayar, ${ }^{[a]}$ Erman Karakuş, $^{[a, c]}$ Tuğrul Güner, $_{,}^{[b]}$ Busra Yildiz, ${ }^{[a]}$ Umit Hakan Yildiz, ${ }^{[a, d, ~ e] ~}$ and \\ Mustafa Emrullahoğlu*a]
}

\begin{abstract}
A boron-dipyrromethene (BODIPY)-based fluorescent probe with a phosgene-specific reactive motif shows remarkable selectivity toward phosgene, in the presence of which the nonfluorescent dye rapidly transforms into a new structure and induces a fluorescent response clearly observable to the naked eye under ultraviolet light. Given that dynamic, a prototypical handheld phosgene detector with a promising sensing capability that expedites the detection of gaseous phosgene without sophisticated instrumentation was developed. The proposed method using the handheld detector involves a rapid response period suitable for issuing early warnings during emergency situations.
\end{abstract}

Phosgene $\left(\mathrm{COCl}_{2}\right)$ is a highly toxic fuming liquid widely used to produce bulk chemicals and pharmaceuticals. Despite its contemporary industrial applications, phosgene has historically suffered a bad reputation owing to its use as a chemical warfare agent in World War I. ${ }^{[1]}$ Its mild odour, resembling freshly mown hay, and its colourlessness render phosgene nearly undetectable, even in excessive amounts. Phosgene inhalation severely affects the respiratory tract and lungs, and phosgene poisoning, with symptoms that appear hours after exposure to the chemical, often cause death by suffocation. ${ }^{[2]}$ Nevertheless,

[a] M. Sayar, Dr. E. Karakuş, B. Yildiz, Dr. U. H. Yildiz, Dr. M. Emrullahoğlu Department of Chemistry, Faculty of Science

Izmir Institute of Technology, Urla, 35430, Izmir (Turkey)

E-mail: mustafaemrullahoglu@iyte.edu.tr

[b] T. Güner

Department of Materials Science and Engineering

Izmir Institute of Technology, Urla, 35430, Izmir (Turkey)

[c] Dr. E. Karakuş

Chemistry Group Laboratories TUBITAK National Metrology Institute (UME) 41470, Gebze-Kocaeli (Turkey)

[d] Dr. U. H. Yildiz

Department of Photonic Science and Engineering

Izmir Institute of Technology, Urla, 35430, Izmir (Turkey)

[e] Dr. U. H. Yildiz

Inovasens Co. Izmir Technology Development Zone Inc. Teknopark, 35430 Urla, Izmir (Turkey)

[**] boron-dipyrromethene

$\square$ Supporting information and the ORCID identification number(s) for the au-

(iD thor(s) of this article can be found under https://doi.org/10.1002/ chem. 201705613 the high toxicity, easy production, and widespread availability in the chemical industry, make phosgene an attractive agent for chemical terrorism. The need for its detection is critical not only to protect civilians against terrorist plots, but also to alert workers to its leakage in industrial plants.

Recent progress on the critical subject of detection has enriched current knowledge for designing molecular probes, especially for phosgene. ${ }^{[3-10]}$ In general, detecting phosgene with a molecular probe involves trapping the molecule using a reactive site (e.g., hydroxy and amine functional groups), which, following structural modification, generates a detectable optical signal, for example a colour change or fluorescence emission.

The analytical performance of such probes depends heavily on the specificity of the recognition unit employed in the probe skeleton. Scheme 1 depicts general detection strategies,

a)

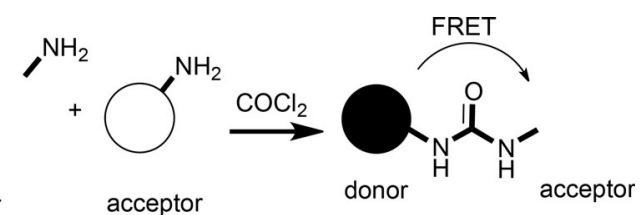

Rudkevich M. (2007)

b)

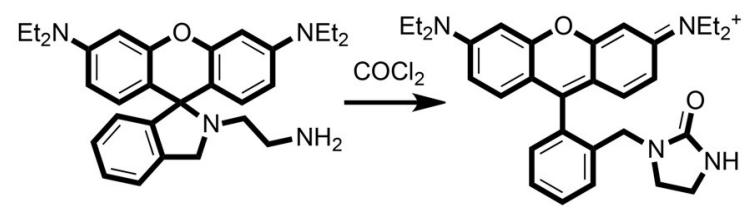

Han S. (2012)

c)

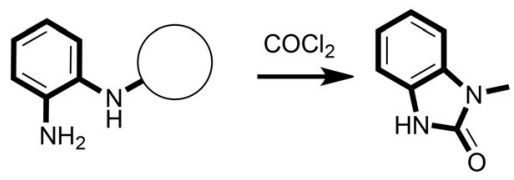

Yoon J. (2016)

Song Q,-H (2017)

Wu S. (2017)

d)

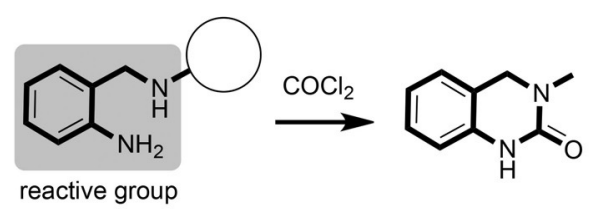

This work

Scheme 1. Reaction schemes for trapping phosgene. 
which involve trapping phosgene through a chemical reaction. Among widely used recognition units, ${ }^{[4-10]}$ o-phenylenediamine (OPA) is unique given its exceptional specificity for phosgene (Scheme $1 \mathrm{c}$ ). In most cases, the OPA unit appended on the fluorophore core can efficiently quench fluorophore emission during a photo-induced electron transfer (PET) process. Eliminating the PET process by inducing a reaction with phosgene is the most efficient method of restoring the fluorescence emission.

Despite notable achievements in detecting phosgene, differentiating phosgene from analytes with similar chemical structures remains a significant challenge, as do low sensitivity and prolonged response times. New probe constructs that use easily accessible recognition/reactive units with improved analytical performance in terms of sensitivity, analyte specificity, and response times are therefore necessary.

In response to that need, herein we present the design, synthesis, and spectral investigation of a novel probe construct that exploits a unique reaction scheme that recognises phosgene with excellent selectivity over other analytes. For our probe design, we used a boron-dipyrromethene (BODIPY) dye as the signal reporter, given its outstanding photophysical properties, ${ }^{[11]}$ as well as an 0 -aminobenzyl amine group as the phosgene-specific reactive motif, which marks a first for research in phosgene sensing (Scheme $1 \mathrm{~d}$ ).

Anticipating that phosgene would interact with the probe reactive site to mediate a cyclization reaction and thereby block the PET process that would in turn induce a turn-on fluorescent response (Scheme 2), we integrated the reactive unit

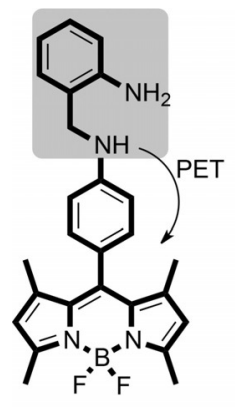

fluorescence "off"

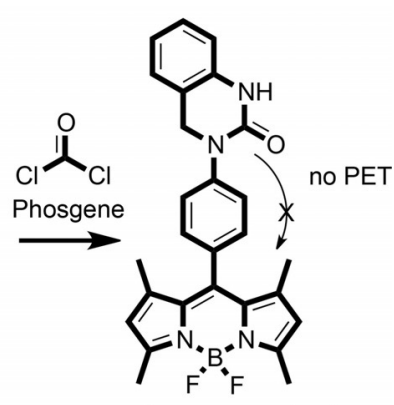

fluorescence "on"
Scheme 2. Reaction-based detection of phosgene.

with the BODIPY core following the synthetic route as outlined in Scheme 3. To that end, we obtained a free-amine derivative of a BODIPY dye, BOD- $\mathrm{NH}_{2}$, by reducing the meso- $\mathrm{NO}_{2}$-phenyl derivative (1). Further alkylation of $\mathrm{BOD}-\mathrm{NH}_{2}$ with the individually prepared compound $\mathbf{2}$ and subsequent reduction yielded a sufficient amount of the title compound, BOD-SYR. ${ }^{[12]}$

We investigated the spectroscopic response of BOD-SYR to the addition of phosgene and other species with a similar reactive nature by using ultraviolet-visible and fluorescence spectroscopy. For the spectral investigation, we used triphosgene as a comparatively safe phosgene source, which instantly transforms into phosgene in the presence of tertiary amines. As expected, the BOD-SYR solution (acetonitrile, with $0.1 \%$<smiles></smiles>

1

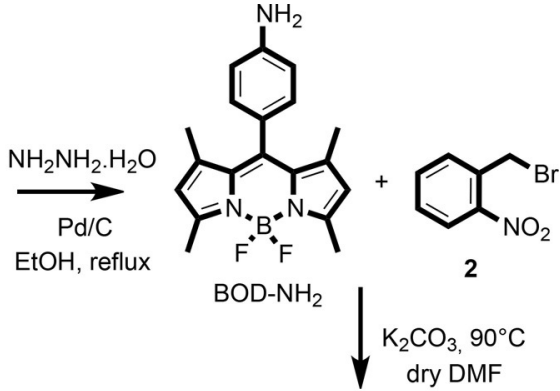<smiles>CCC1c2ccc(C)n2P[N+]2(F)C(C)CC(C)N2C1c1ccc(NCc2ccccc2N)cc1</smiles>

BOD-SYR

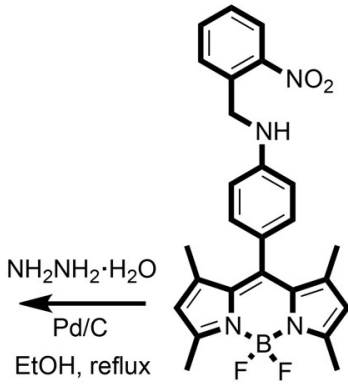

BOD-NO
Scheme 3. Stepwise synthesis of BOD-SYR.

$\left.\mathrm{Et}_{3} \mathrm{~N}\right)$, exhibited no emission $\left(\Phi_{\mathrm{F}}=0.005\right)$ in the visible region owing to PET-promoted quenching arising from the mesoamine moiety. However, upon the addition of triphosgene (1 equiv), an intense emission band appeared at $511 \mathrm{~nm}$ (Figure 1). Notably, the spectroscopic response of the probe was rapid, and we observed the complete saturation of signal intensity within ten seconds (see Figure S2 in the Supporting Information).

Upon the systematic addition of triphosgene, the emission band at $511 \mathrm{~nm}$ increased linearly, and its intensity peaked with the addition of 6 equiv of triphosgene, with an enhancement factor of more than 300 -fold. In light of analytical data collected from the titration experiment, we estimate the lower limit of detection to be $179 \mathrm{~nm}$ given a signal-to-noise ratio (S/

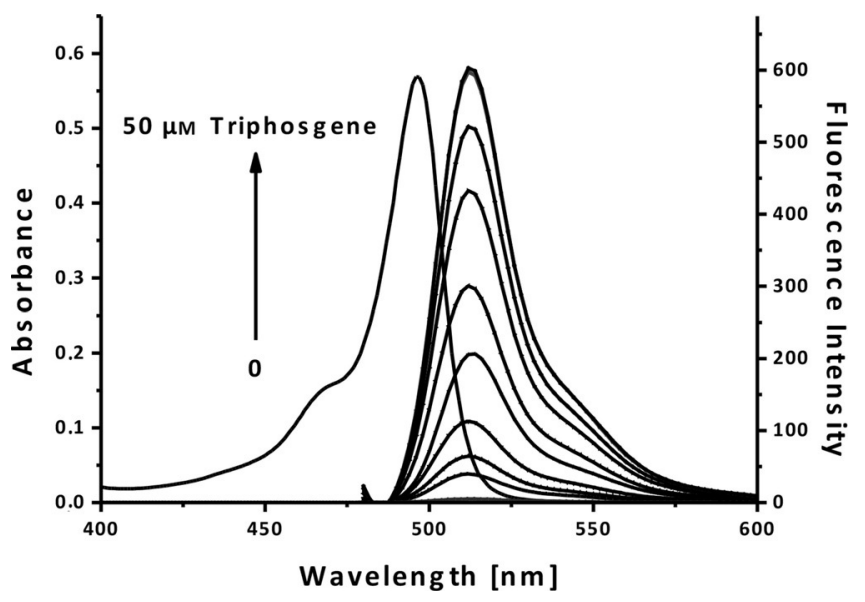

Figure 1. Absorbance and fluorescence spectra of BOD-SYR (10 $\mu \mathrm{M})$ upon gradual addition of a solution of triphosgene $(0-50 \mu \mathrm{M})$ in acetonitrile $\left(\mathrm{CH}_{3} \mathrm{CN}\right.$, with $\left.0.1 \% \mathrm{Et}_{3} \mathrm{~N}\right), \lambda_{\mathrm{ex}}=460 \mathrm{~nm}$. 
$\mathrm{N})=3 .^{[12]}$ The emission became distinctly green upon contact with phosgene, which we attributed to a modification of the dye structure (Scheme 2). A new green-emissive compound, monitored on a thin-layer chromatography plate, was also clear evidence of the formation of a new BODIPY derivative. After purification with column chromatography we confirmed the identity of the new BODIPY structure as the cyclization product of the probe by using nuclear magnetic resonance spectroscopy (NMR) and mass analysis. Given the chemical identity of the isolated product, the recognition of phosgene may proceed by a sequential process initiated upon nucleophilic substitution of phosgene with the primary aryl amine, which promoted an intramolecular cyclization to yield a new BODIPY structure, BOD-UREA $\left(\Phi_{\mathrm{F}}=0.52\right)$, with a cyclic urea located on the meso position (Scheme 4).

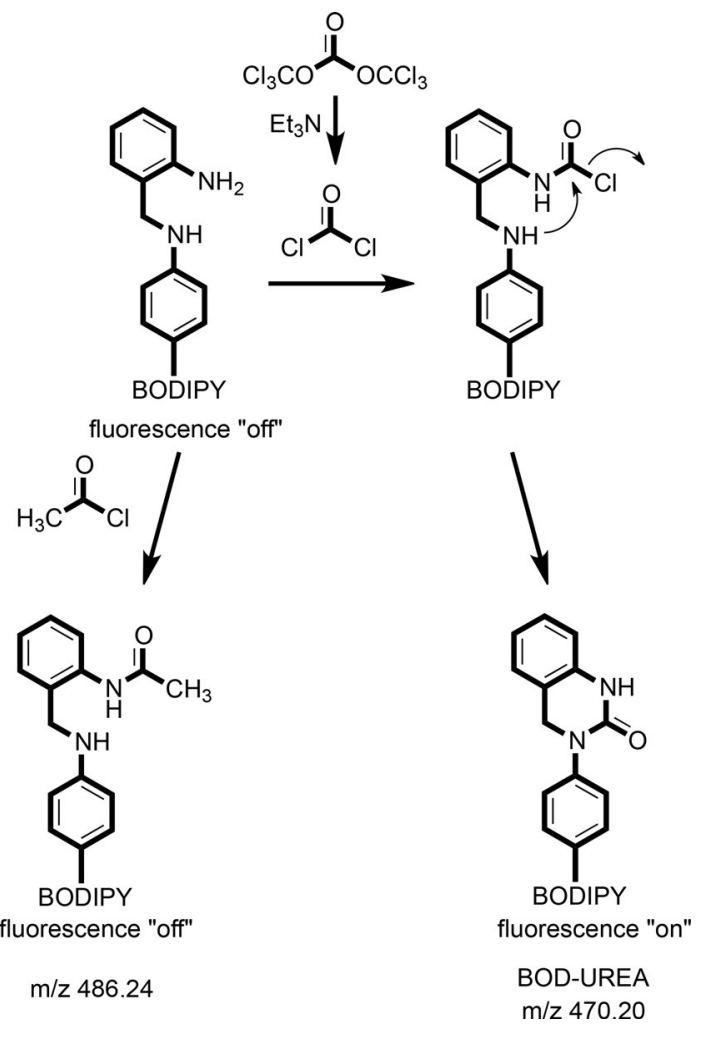

Scheme 4. Proposed reaction mechanism for the trapping of triphosgene.

We additionally investigated the spectroscopic behaviour of the probe in the presence of other potentially reactive species. Using identical sensing conditions, we observed no significant change in fluorescence for other reactive analytes, including acyl chlorides such as acetyl chloride, oxalyl chloride $\left[(\mathrm{COCl})_{2}\right]$, thionyl chloride $\left(\mathrm{SOCl}_{2}\right)$, phosphorus oxychloride $\left(\mathrm{POCl}_{3}\right)$, tosyl chloride $(\mathrm{TsCl})$, and the nerve agent mimic diethylchlorophosphate (DCP; Figure 2). With electrophiles such as acetyl chloride, mono substitution from the primary amine eliminated the cyclization step (Scheme 4), which clearly accounts for the exceptional selectivity of BOD-SYR towards phosgene. ${ }^{[12]}$

The promising efficiency of BOD-SYR in sensing phosgene in the solution encouraged us to further assess its feasibility to

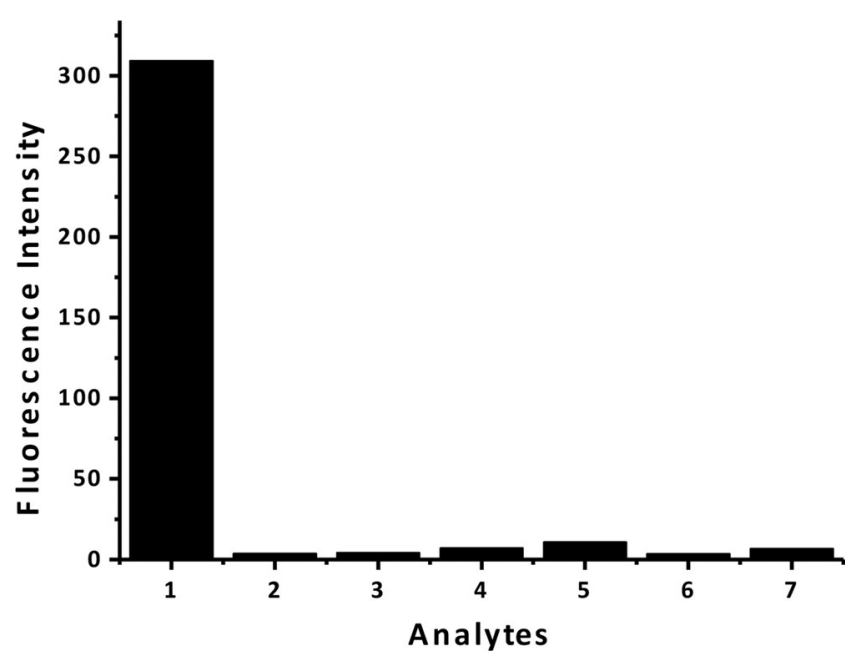

Figure 2. Fluorescence intensity change of BOD-SYR $\left[10 \mu \mathrm{M}\right.$, in $\mathrm{CH}_{3} \mathrm{CN} / \mathrm{Et}_{3} \mathrm{~N}$ $(0.1 \%)]$ recorded $2 \mathrm{~min}$ after the addition of various analytes (10 equiv; $\lambda_{\mathrm{ex}}=460 \mathrm{~nm}$ ). 1) Triphosgene, 2) $\mathrm{POCl}_{3}$, 3) $\left.\left.\left.\mathrm{DCP}, 4\right)(\mathrm{COCl})_{2}, 5\right) \mathrm{SOCl}_{2}, 6\right) \mathrm{TsCl}$, 7) $\mathrm{CH}_{3} \mathrm{COCl}$.

detect gaseous phosgene generated in situ. Seeking to develop an alternative detection strategy that could immediately detect phosgene at exposure sites, we designed a paper-based indicator cartridge to facilitate image capturing and the differentiation of colour development. We treated the paper circles on the cartridge with a fixed concentration $(1.0 \mathrm{~mm})$ of BODSYR to yield a physisorbed layer of the probe, after which we placed the cartridge in sealed tubes and exposed it to varying concentrations of phosgene $(0-100 \mathrm{ppm})$ generated in situ from the triphosgene- $\mathrm{Et}_{3} \mathrm{~N}$ coupling. Next, we placed the cartridge in a black-box apparatus equipped with ultraviolet lightemitting diodes in front of smartphone camera (Figure 3a). ${ }^{[12]}$ We captured the digital images of the cartridge in Figure $3 \mathrm{~b}$ prior to phosgene exposure. As Figure $3 \mathrm{c}$ illustrates, an intensifying colour development was observable as the concentration increased. Shown from left to right, the concentration of ana- (a) Smart Phone-based Detector

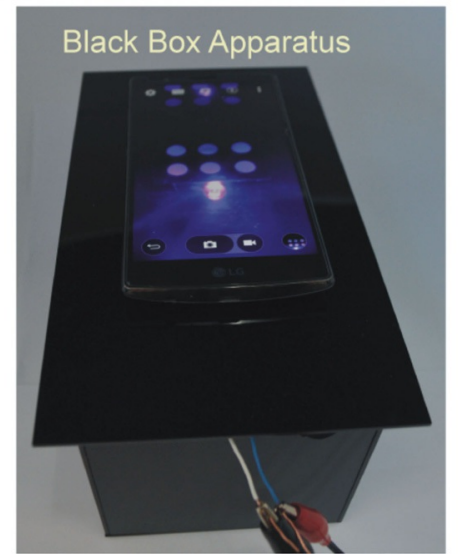

(b)

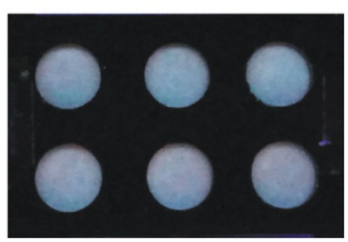

(c)

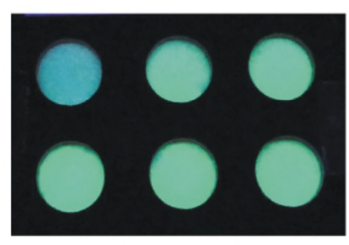

Figure 3. a) Image of the black-box apparatus and paper-based indicator cartridge. b) Image of indicator cartridge prior to UV illumination. c) Image of indicator cartridge under UV illumination (top row: concentration $=0,10$ and $25 \mathrm{ppm}$; bottom row: concentration $=50,75$ and $100 \mathrm{ppm}$ ). 
lytes in the top row ranged from $0-25 \mathrm{ppm}$ and, in the bottom row, from 50-100 ppm.

We analysed each spot by using simple colour code detection, which revealed the change in red and green components on a scale of $0-255$ correlated to the concentration of phosgene. As Figure 4 a depicts, the red component changed from 98 to $45 \pm 8$ as the concentration varied from 0 to $100 \mathrm{ppm}$, whereas the green component increased from 100 to 190 . This promising colour-code correlation to the concentration of phosgene yielded a calibration curve enabling the quantification of gaseous phosgene (Figure 4c). The linear relationship of red and green components with variable concentration

(a)

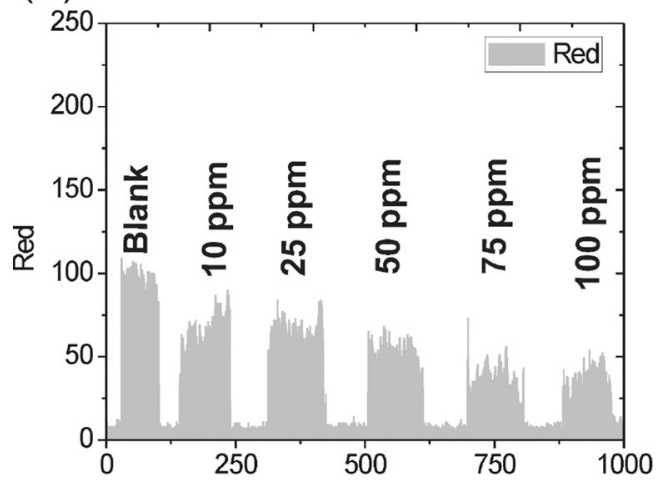

(b)

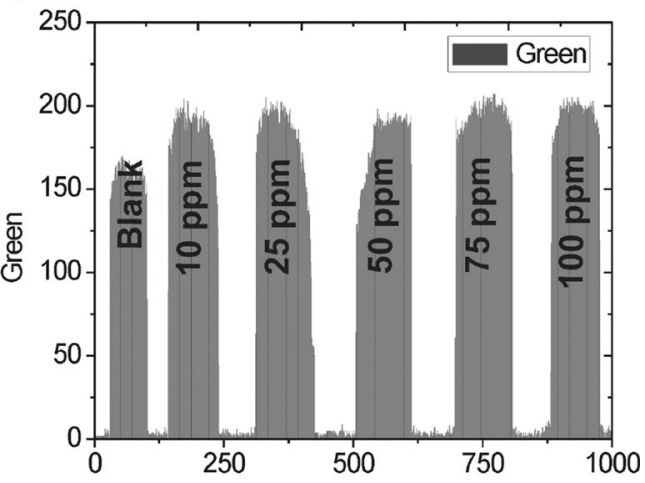

(c)

Row Numbers

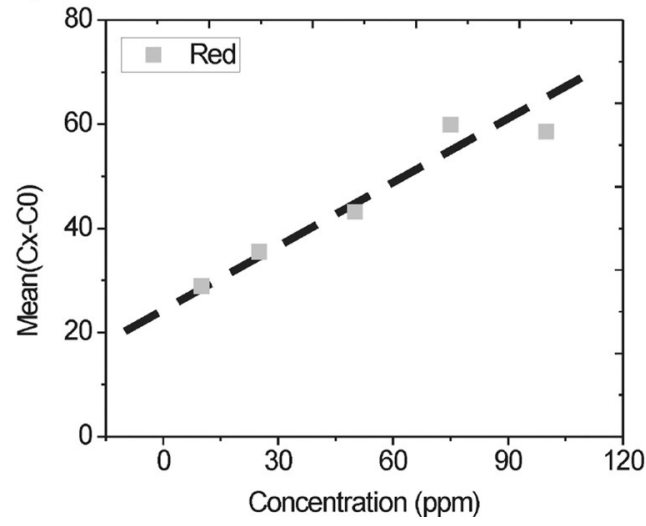

Figure 4. a) Colour code analysis (0-255) of phosgene-exposed indicator cartridge based on the red component. b) Colour code analysis of phosgeneexposed indicator cartridge based on the green component. c) Calibration curve based on red component versus phosgene concentration. show promise for detecting and quantifying phosgene using simple image analysis. The BOD-SYR indicator cartridges and black-box apparatus may therefore be applicable to translating ordinary smartphones into phosgene detectors without complicated fabrication processes.

The analytical performance of paper strips toward gaseous phosgene was also investigated by fluorescence spectroscopy. The emission intensity increased immediately upon exposure to phosgene (e.g., $50 \mathrm{ppm}$ ) then reached to a plateau within $10 \mathrm{~s}$ (Figure 5). The limit of detection (LOD) based on fluorometric analysis was found to be as $10 \mathrm{ppm}$ (Supporting Information), which is considerably lower than fatal levels. ${ }^{[13]}$

In summary, we have developed a phosgene-specific fluorescent probe that uses a BODIPY dye as a visible light-harvesting chromophore and an o-aminobenzyl amine unit as the newgeneration reactive motif. Our probe system relying on a sixmembered cyclization process exhibits comparable analytical performance to previously described systems in terms of selectivity and sensitivity, yet with an improved response time $\left(<10 \mathrm{~s}\right.$; Table S1). ${ }^{[12]}$ Along with its rapid, specific response to
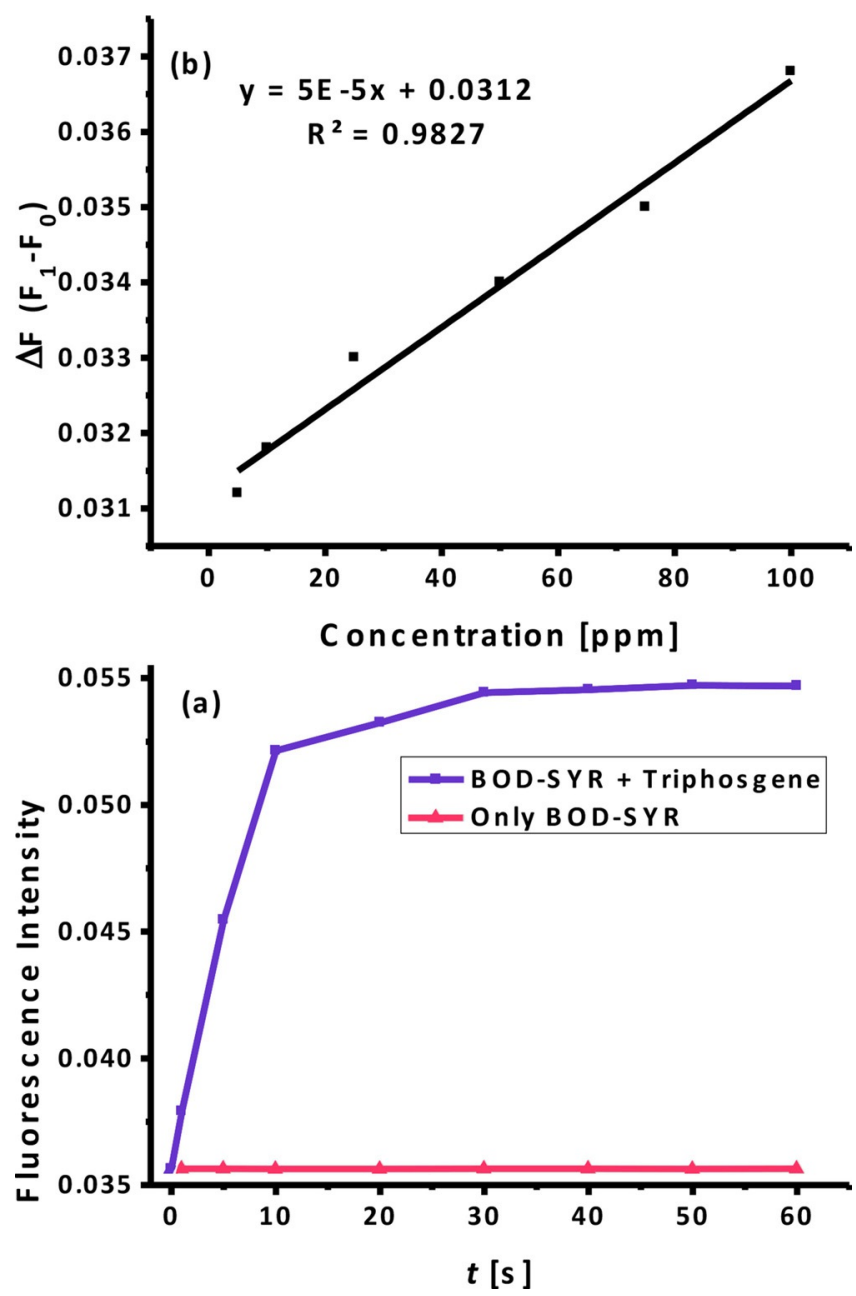

Figure 5. a) Fluorescence intensity change of BOD-SYR-loaded paper strips in the presence of $50 \mathrm{ppm}$ gaseous phosgene as a function of time $\left(\lambda_{\mathrm{ex}}=460 \mathrm{~nm}\right)$. b) Fluorescence intensity change of BOD-SYR-loaded paper strips as a function of phosgene concentration (0-100 ppm). 
triphosgene in solution, the probe proved successful in detecting gaseous phosgene when fabricated on a solid surface. The prototype handheld phosgene detector using dye-loaded cartridges exhibited promising sensing capability that expedited the detection of phosgene gas without sophisticated instrumentation requiring only a smartphone as a photometric detector. Most importantly, the proposed method and the handheld detector afford a rapid response period suitable for the early detection of phosgene in emergency situations.

\section{Experimental Section}

\section{Synthesis of BOD-SYR}

BOD- $\mathrm{NO}_{2}(50 \mathrm{mg}, 0.11 \mathrm{mmol})$ in $\mathrm{EtOH}(8 \mathrm{~mL})$ was added to a solution of $\mathrm{NH}_{2} \mathrm{NH}_{2} \cdot \mathrm{H}_{2} \mathrm{O}(95 \mu \mathrm{L})$ and $\mathrm{Pd} / \mathrm{C}(10.1 \mathrm{mg}, 0.01 \mathrm{mmol})$. The reaction mixture was heated at reflux under $\mathrm{Ar}$ atmosphere for $2 \mathrm{~h}$, then was cooled to room temperature and filtered. The solids were washed with DCM. The liquid phases residue was purified by column chromatography. (2:1 hexane/ethyl acetate) to afford BODSYR as orange solid $\left(20 \mathrm{mg}, 40 \%\right.$ yield). ${ }^{1} \mathrm{H}$ NMR $\left(400 \mathrm{MHz}, \mathrm{CDCl}_{3}\right)$ $\delta=7.23-7.15(\mathrm{~m}, 2 \mathrm{H}), 7.07(\mathrm{td}, J=2.3,8.6 \mathrm{~Hz}, 2 \mathrm{H}), 6.81-6.74(\mathrm{~m}$, $4 \mathrm{H}), 5.98$ (s, 2H), 4.26 (br. s., $2 \mathrm{H}), 4.07$ (br. s, 2H), 3.96 (br. s, 1H), $2.55(\mathrm{~s}, 6 \mathrm{H}), 1.51 \mathrm{ppm}(\mathrm{s}, 6 \mathrm{H}) .{ }^{13} \mathrm{C}$ NMR $\left(100 \mathrm{MHz}, \mathrm{CDCl}_{3}\right) \delta=154.9$, 148.8, 145.6, 143.2, 142.6, 130.1, 129.2, 129.0, 124.3, 122.4, 120.9, $118.6,116.1,113.8,46.8,14.8,14.6 \mathrm{ppm}$. HRMS (QTOF): $\mathrm{m} / \mathrm{z}$ calcd (\%) for $\mathrm{C}_{26} \mathrm{H}_{27} \mathrm{BF}_{2} \mathrm{~N}_{4}$ : $445.2330[\mathrm{M}+\mathrm{H}]^{+}$; found: $445.2443[\mathrm{M}+\mathrm{H}]^{+}$

\section{Synthesis of BOD-UREA}

BOD-SYR (10 mg, $0.025 \mathrm{mmol}$ ) was dissolved in dry DCM (2 mL). Then, triphosgene solution (125 $\mathrm{mm}$ in dry DCM) was added drop by drop to the BOD-SYR solution under Ar for 10 min. After evaporation of solvent, the resultant residue was purified by column chromatography (2:1 hexane/ethyl acetate) to afford BOD-UREA (3 mg, $26 \%$ yield). ${ }^{1} \mathrm{H}$ NMR $\left(400 \mathrm{MHz}, \mathrm{CDCl}_{3}\right) \delta=7.54(\mathrm{~d}, J=8.4$, $2 \mathrm{H}), 7.32(\mathrm{~d}, J=8.4,2 \mathrm{H}), 7.17-7.15(\mathrm{~m}, 1 \mathrm{H}), 7.05-7.02(\mathrm{~m}, 1 \mathrm{H}), 6.88$ $(\mathrm{s}, 1 \mathrm{H}), 6.79-6.77(\mathrm{~m}, 1 \mathrm{H}), 5.99(\mathrm{~s}, 2 \mathrm{H}), 4.91(\mathrm{~s}, 2 \mathrm{H}), 2.56(\mathrm{~s}, 6 \mathrm{H})$, $1.47 \mathrm{ppm}(\mathrm{s}, 6 \mathrm{H}) .{ }^{13} \mathrm{C}$ NMR $\left(100 \mathrm{MHz}, \mathrm{CDCl}_{3}\right) \delta=155.6,153.3,136.3$, $132.1,128.7,128.4,125.6,125.0,122.6,121.3,118.2,113.6,75.4$, $51.1,14.7,14.6 \mathrm{ppm}$. HRMS (QTOF): $\mathrm{m} / \mathrm{z}$ calcd (\%) for $\mathrm{C}_{27} \mathrm{H}_{25} \mathrm{BF}_{2} \mathrm{~N}_{4} \mathrm{O}$ : $471.2123[M+\mathrm{H}]^{+}$; found: $471.2223[M+\mathrm{H}]^{+}$.

\section{Acknowledgements}

The authors gratefully acknowledge İzmir Institute of Technology and TÜBA-GEBIP-2016 (Turkish Academy of Science) for financial support.

\section{Conflict of interest}

The authors declare no conflict of interest.
Keywords: BODIPY • fluorescence • handheld detectors phosgene $\cdot$ photodetection

[1] a) C. B. Bast, D. F. Glass-Mattie in Handbook of Toxicology of Chemical Warfare Agents, 2nded. (Ed.: R. C. Gupta), Academic Press, Boston, 2015, pp. 327-335; b) M. C. Winternitz, Pathology of War Gas Poisoning, Yale University Press, New Haven, CT, 1920, pp. 33-66; c) A. M. Prentiss, Chemicals in War, 1st ed.; McGraw-Hill, New York, 1937, pp. 216-217.

[2] a) L. S. Hardison, E. Wright, A. F. Pizon, J. Med. Toxicol. 2014, 10, 51-56; b) S. A. Cucinell, Arch. Environ. Health 1974, 28, 272-275; c) A. M. Sciuto, P. T. Strickland, T. P. Kennedy, Y. Guo, G. H. Gurtner, J. Appl. Physiol. 1996, 80, 149-157; d) A. M. Sciuto, Arch. Toxicol. 1998, 72, 283-288; e) L. Karalliedde, H. Wheeler, R. Maclehose, V. Murray, Public Health 2000, 114, 238-248; f) W. W. Holmes, B. M. Keyser, D. C. Paradiso, R. Ray, D. K. Andres, B. J. Benton, C. C. Rothwell, H. M. Hoard Fruchey, J. F. Dillman, A. M. Sciuto, D. R. Anderson, Toxicol. Lett. 2016, 244, 8-20.

[3] For recent reviews, see: a) X. Li, X. Gao, W. Shia, H. Ma, Chem. Rev. 2014, 114, 590-659; b) K. P. Carter, A. M. Young, A. E. Palmer, Chem. Rev. 2014, 114, 4564-4601; c) Z. Guo, S. Park, J. Yoon, I. Shin, Chem. Soc. Rev. 2014, 43, 16-29; d) X. Su, I. Aprahamian, Chem. Soc. Rev. 2014, 43, $1963-$ 1981 ; e) X. Chen, T. Pradhan, F. Wang, J. S. Kim, J. Yoon, Chem. Rev. 2012, 112, 1910-1956; f) H. Zheng, X.-Q. Zhan, Q.-N. Biana, X.-J. Zhang, Chem. Commun. 2013, 49, 429-447; g) X. Zhou, S. Lee, Z. Xu, J. Yoon, Chem. Rev. 2015, 115, 7944-8000.

[4] H. Zhang, D. M. Rudkevich, Chem. Commun. 2007, 1238-1239.

[5] X. Wu, Z. Wu, Y. Yang, S. Han, Chem. Commun. 2012, 48, 1895-1897.

[6] D. Feng, Y. Zhang, W. Shi, X. Li, H. Ma, Chem. Commun. 2010, 46, 9203 9205.

[7] a) P. Kundu, K. C. Hwang, Anal. Chem. 2012, 84, 4594-4597.

[8] a) H.-C. Xia, X.-H. Xu, Q.-H. Song, ACS Sens. 2017, 2, 178-182; b) S.-L. Wang, L. Zhong, Q.-H. Song, Chem. Commun. 2017, 53, 1530-1533; c) H.-C. Xia, X.-H. Xu, Q.-H. Song, Anal. Chem. 2017, 89, 4192-4197; d) H. Xie, Y. Wu, F. Zeng, J. Chen, S. Wu, Chem. Commun. 2017, 53, 9813-9816.

[9] a) X. Zhou, Y. Zeng, C. Liyan, X. Wu, J. Yoon, Angew. Chem. Int. Ed. 2016, 55, 4729-4733; Angew. Chem. 2016, 128, 4807-4811; b) Y. Hu, L. Chen, H. Jung, Y. Zeng, S. Lee, K. M. K. Swamy, X. Zhou, M. H. Kim, J. Yoon, ACS Appl. Mater. Interfaces 2016, 8, 22246-22252; c) L. Chen, D. Wu, J.-M. Kim, J. Yoon, Anal. Chem. 2017, 89, 12596-12601; d) W.-Q. Zhang, K. Cheng, X. Yang, Q.-Y. Li, H. Zhang, Z. Ma, H. Lu, H. Wub, X.-J. Wang, Org. Chem. Front. 2017, 4, 1719-1725.

[10] Y. Zhang, A. Peng, X. Jie, Y. Lv, X. Wang, Z. Tian, ACS Appl. Mater. Interfaces 2017, 9, 13920-13927.

[11] a) G. Ulrich, R. Ziessel, A. Harriman, Angew. Chem. Int. Ed. 2008, 47, 1184-1201; Angew. Chem. 2008, 120, 1202-1219; b) T. Kowada, H. Maeda, K. Kikuchi, Chem. Soc. Rev. 2015, 44, 4953-4972; c) Y. Ni, J. Wu, Org. Biomol. Chem. 2014, 12, 3774-3791; d) A. Loudet, K. Burgess, Chem. Rev. 2007, 107, 4891-4932; e) H. Lu, J. Mack, Y. Yang, Z. Shen, Chem. Soc. Rev. 2014, 43, 4778-4823; f) S. Kolemen, E. U. Akkaya, Coord. Chem. Rev. 2018, 354, 121-134.

[12] For more details see the Supporting Information.

[13] W. Braker, A. Mossman, Matheson Gas Data Book, 6th ed., Matheson, South Tarra, VIC, Australia, 1980, pp. 596.

Manuscript received: November 26, 2017

Accepted manuscript online: January 5, 2018

Version of record online: February 5, 2018 